\title{
Heavy cluster decay of trans-zirconium "stable" nuclides
}

\author{
D. N. Poenaru* \\ Institut für Theoretische Physik der J. W. Goethe-Universität, \\ Frankfurt am Main, West Germany \\ W. Greiner \\ Institut für Theoretische Physik der J. W. Goethe-Universität, \\ Frankfurt am Main, West Germany \\ and Joint Institute for Heavy Ion Research, Oak Ridge, Tennessee 37830 \\ M. Ivascu \\ Central Institute of Physics, Bucharest, Romania \\ A. Sandulescu \\ Joint Institute for Nuclear Research, Dubna, U.S.S.R. \\ (Received 30 May 1985)

\begin{abstract}
By using the analytical superasymmetric fission model it is shown that all "stable" nuclei lighter than lead with $Z>40$ are metastable relative to the spontaneous emission of nuclear clusters. An even-odd effect is included in the zero point vibration energy. Half-lives in the range $10^{40}-10^{50} \mathrm{~s}$ are obtained for $Z>62$. The region of metastability against these new decay modes is extended beyond that for $\alpha$ decay and in some cases, in the competing region, the emission rates for nuclear clusters are larger than for $\alpha$ decay.
\end{abstract}

During the last few years advances in studies of many nuclear decay modes have gained considerable interest. Recently, these have been reviewed by Hamilton et al. ${ }^{1}$ We have used (see Refs. 2-4, and references therein) several methods to show that nuclei heavier than $\alpha$ particles $\left(A_{2}>4\right)$ and lighter than fission fragments $\left(A_{2}<70\right)$ are spontaneously emitted from various parent nuclides $(A, Z)$ leading to the daughters $\left(A_{1}, Z_{1}\right)$. A review paper presenting our early work will be published elsewhere. ${ }^{5}$

There is, already, experimental evidence concerning two of more than 140 new decay modes: ${ }^{6,7}$ (1) ${ }^{14} \mathrm{C}$ spontaneous emission ${ }^{8-12}$ from ${ }^{223} \mathrm{Ra}$ and ${ }^{11}$ from ${ }^{222,224} \mathrm{Ra}$ and $(2){ }^{24} \mathrm{Ne}$ radioactivity ${ }^{13}$ of ${ }^{232} \mathrm{U}$ and ${ }^{14}$ of ${ }^{231} \mathrm{~Pa}$.

The experimental data are in agreement with the halflives and the branching ratios relative to $\alpha$ decay calculated $^{5-7,15}$ (see also Refs. 16 and 17) in the framework of the analytical superasymmetric fission model (ASAFM) 3,18 and with the branching ratios computed by Shi and Swiatecki ${ }^{19}$ using a proximity-plus-Coulomb potential.

Up to now only the region of parent nuclides with $Z>82$ have been investigated. The purpose of this paper is to extend the domain for nuclides lighter than lead, pointing out that all the so-called "stable" nuclides with atomic numbers $Z>40$, are, in fact, metastable with respect to several new cluster decay modes.

In order to estimate the half-lives, $T^{\prime}$ and $T$, relative to nuclear cluster emission we shall use $\mathrm{ASAFM}^{7}$ with two values of the zero point vibration energy $E_{v}$. This energy enters crucially the formula for the lifetime against cluster emission

$$
\begin{array}{r}
T=\frac{h \ln 2}{2 E_{v}} \exp \left(\frac{2}{\hbar} \int_{R_{a}}^{R_{b}}\left\{2 \mu\left[E(r)-Q^{\prime}\right]\right\}^{1 / 2} d r\right), \\
Q^{\prime}=Q+E_{v},
\end{array}
$$

where the standard notations ${ }^{7}$ are used for the reduced mass, $\mu$, the potential interaction energy $E(r)$ and $E\left(R_{a}\right)=E\left(R_{b}\right)=Q^{\prime}$. We choose on the one hand,

$E_{v}=Q\left[0.056+0.039 \exp \left(\frac{4-A_{2}}{2.50}\right)\right] ; Q>0 ; A_{2}>4$,

which leads the half-life $T$, regardless of the odd $(o)$ or even $(e)$ character of the neutron $(N)$ and proton $(Z)$ numbers of the parent nuclide, and on the other hand, with

$$
E_{v}^{\prime}=E_{v} \times\left\{\begin{array}{ll}
1.105, & e-e \\
0.947, & e-o \\
1.000, & o-e \\
0.789, & o-o
\end{array}\right. \text { parent }
$$

leading to the half-life $T^{\prime}$, one can obtain better agreement for $\alpha$ decay of 380 emitters. Hence, $T^{\prime}$ and $T$ are the halflives with or without the even-odd effect taken into account, respectively. A similar even-odd effect was observed ${ }^{20}$ for ${ }^{14} \mathrm{C}$ radioactivity of $\mathrm{Ra}$ isotopes ${ }^{11}$ and of ${ }^{225} \mathrm{Ac}$ : an enhanced cluster emission rate from $e-e$ nuclei, or equivalently a hindrance from $o-e, e-o$, and $o-o$ parents.

The released energy, $Q$, is computed with the new version of the mass table. ${ }^{21}$ We do not consider the relatively small angular momentum carried away by the emitted cluster if the parent or daughter nuclei have a finite spin, because we have shown previously ${ }^{7}$ that the hindrance introduced by the corresponding centrifugal barrier can be ignored, if the cluster is not too small.

Figure 1 shows that from the energetical point of view, spontaneous cluster emission is allowed in a larger region of nuclei than that for $\alpha$ decay. For example, the neutron deficient nucleus ${ }^{67} \mathrm{Se}$, which is stable relative to $\alpha$ decay, can be split into ${ }^{27} \mathrm{Si}+{ }^{40} \mathrm{Ca}(Q=0.37 \mathrm{MeV}),{ }^{28} \mathrm{Si}+{ }^{39} \mathrm{Ca}$ $(Q=1.91 \mathrm{MeV}),{ }^{31} \mathrm{~S}+{ }^{36} \mathrm{Ar}(Q=2.42 \mathrm{MeV})$, and ${ }^{32} \mathrm{~S}+{ }^{35} \mathrm{Ar}$ $(Q=2.20 \mathrm{MeV})$. For $Z>40$, all the nuclei tabulated by Wapstra and Audi, ${ }^{21}$ including the "stable" ones (colored in 


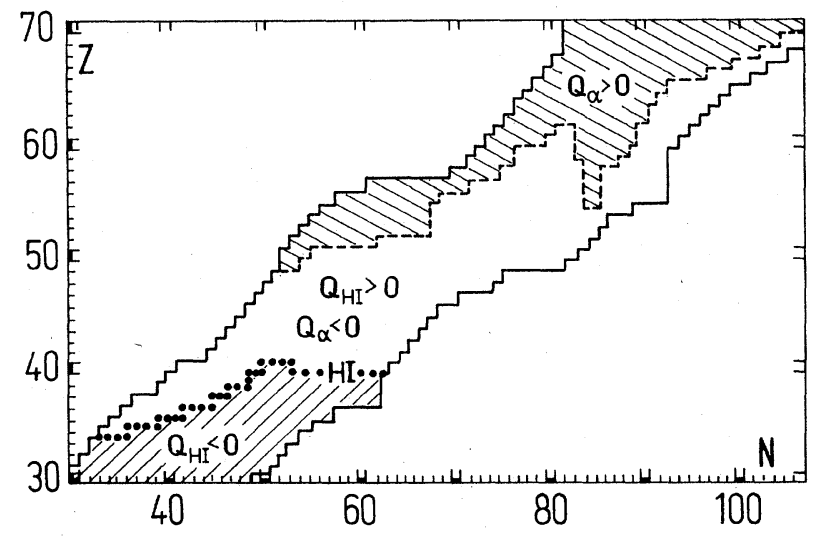

FIG. 1. The lower limits of the regions where $\alpha$ decay (dashed line) and various cluster radioactivities (dotted line) are allowed from energetical point of view.

black on the chart of nuclei ${ }^{22}$ ) are metastable with respect to these new decay modes.

Consequently, it makes sense to search for the most probable decay modes of 156 nuclides with $Z=41-83$, which are listed in Ref. 22 or other charts and tables, without any specification for the half-life. However, if the lifetime of a nucleus is long enough, $T>T_{\max }$, one can from a practical point of view, consider the nuclides to be stable. The questions are, what is $T_{\max }$, which decay chan- nel determines it, and can it be measured? Indeed, measurements of lifetime have reached new limits. For example, half-lives of the order of $10^{25} \mathrm{~s}$ have been measured for the spontaneous fission of some actinides.

In Table I only some of the "stable" parent nuclei with $T<10^{50} \mathrm{~s}$ for cluster emission with $Z_{2} \leqslant 28$ are listed. A more complete table containing also ${ }^{162} \mathrm{Er},{ }^{171,172,174,176} \mathrm{Yb}$, ${ }^{175} \mathrm{Lu},{ }^{176-179} \mathrm{Hf},{ }^{180} \mathrm{Ta},{ }^{190} \mathrm{Os},{ }^{193} \mathrm{Ir},{ }^{194-196} \mathrm{Pt},{ }^{198-201} \mathrm{Hg}$, and ${ }^{203} \mathrm{Tl}$, and many other radioactive nuclei will be published elsewhere. Alpha decay half-lives, $T_{\alpha}$, are estimated with our semiempirical formula. ${ }^{3,5}$

One can see that $T_{\alpha}<10^{30} \mathrm{~s}$ is expected for ${ }^{151} \mathrm{Eu},{ }^{176} \mathrm{Hf}$, ${ }^{180} \mathrm{~W}$, and ${ }^{184,}{ }^{187} \mathrm{Os}$. One has $T<10^{42} \mathrm{~s}$ for ${ }^{16} \mathrm{O}$ emission from ${ }^{156} \mathrm{Dy},{ }^{48} \mathrm{Ca}$ emission from ${ }^{184} \mathrm{~W},{ }^{185} \mathrm{Re}$, and ${ }^{184} \mathrm{Os}$, and for ${ }^{49} \mathrm{Ca}$ emission from ${ }^{187} \mathrm{Os}$. Usually the daughter neutron number is magic or almost magic, $N_{1}=82$, and the daughter proton number is not very far from $Z_{1}=50$. These effects are similar with those observed ${ }^{7,18}$ in the trans-lead region for $N_{1} \simeq 126$ and $Z_{1} \simeq 82$. But in this region one can meet cluster emission rates several times larger than for $\alpha$ particles. For example, ${ }^{16} \mathrm{O}$ from ${ }^{154} \mathrm{Gd}$, ${ }^{32} \mathrm{Si}$ from ${ }^{169} \mathrm{Tm},{ }^{48} \mathrm{Ca}$ from ${ }^{176} \mathrm{Yb},{ }^{180} \mathrm{Hf},{ }^{181} \mathrm{Ta}$, and ${ }^{183,}{ }^{184} \mathrm{~W}$, ${ }^{50} \mathrm{Ca}$ from ${ }^{186} \mathrm{~W},{ }^{58} \mathrm{Cr}$ from ${ }^{192} \mathrm{Os},{ }^{68} \mathrm{Ni}$ from ${ }^{198} \mathrm{Pt}$ and ${ }^{202} \mathrm{Hg}$, and ${ }^{62} \mathrm{Fe}$ from ${ }^{197} \mathrm{Au}$.

In conclusion, according to our estimates in the framework of ASAFM the so-called "stable" nuclei with $Z>60$ are expected to decay spontaneously, by emission of clusters like ${ }^{12} \mathrm{C},{ }^{16} \mathrm{O},{ }^{30,32} \mathrm{Si},{ }^{48,50} \mathrm{Ca}$, and ${ }^{68} \mathrm{Ni}$ with half-lives $T>10^{40} \mathrm{~s}$, leading to daughters with $Z_{1}=50-58$ and $N_{1} \simeq 78-82$.

TABLE I. Some "stable" nuclides with half-life $T$ in respect to heavy cluster emission shorter than $10^{50} \mathrm{~s}$.

\begin{tabular}{|c|c|c|c|c|c|c|c|c|c|c|}
\hline \multirow[b]{2}{*}{ Nuclide } & \multirow{2}{*}{$\begin{array}{c}\text { Emitted } \\
\text { heavy ion }\end{array}$} & \multicolumn{2}{|c|}{ Daughter } & \multirow{2}{*}{$\begin{array}{c}Q \\
(\mathrm{MeV})\end{array}$} & \multirow{2}{*}{$\begin{array}{c}Q_{\alpha} \\
(\mathrm{MeV})\end{array}$} & \multirow{2}{*}{$\begin{array}{c}\log T_{\alpha} \\
\quad(\mathrm{s})\end{array}$} & \multirow{2}{*}{$\begin{array}{l}\log T \\
(\mathrm{~s})\end{array}$} & \multirow{2}{*}{$\begin{array}{r}\log T^{\prime} \\
(\mathrm{s})\end{array}$} & \multirow[b]{2}{*}{$\log \left(\frac{T}{T_{\alpha}}\right)$} & \multirow[b]{2}{*}{$\log \left(\frac{T^{\prime}}{T_{\alpha}^{\prime}}\right)$} \\
\hline & & $Z_{1}$ & $N_{1}$ & & & & & & & \\
\hline${ }^{150} \mathrm{Sm}$ & ${ }^{12} \mathrm{C}$ & 56 & 82 & 11.21 & 1.45 & 35.8 & 48.8 & 48.3 & 13.0 & 12.5 \\
\hline${ }^{151} \mathrm{Eu}$ & & 57 & 82 & 12.57 & 1.96 & 25.7 & 42.7 & 42.7 & 17.0 & 17.0 \\
\hline${ }^{154} \mathrm{Gd}$ & ${ }^{16} \mathrm{O}$ & 56 & 82 & 19.29 & 0.92 & 60.4 & 48.5 & 48.0 & -11.9 & -12.4 \\
\hline${ }^{156} \mathrm{Dy}$ & & 58 & 82 & 22.29 & 1.76 & 32.2 & 41.1 & 40.5 & 8.8 & 8.3 \\
\hline${ }^{169} \mathrm{Tm}$ & ${ }^{32} \mathrm{Si}$ & 55 & 82 & 49.36 & 1.20 & 54.7 & 48.3 & 48.3 & -6.4 & -6.4 \\
\hline${ }^{168} \mathrm{Yb}$ & ${ }^{30} \mathrm{Si}$ & 56 & 82 & 51.13 & 1.95 & 32.1 & 45.5 & 44.6 & 13.3 & 12.5 \\
\hline${ }^{170} \mathrm{Yb}$ & ${ }^{32} \mathrm{Si}$ & 56 & 82 & 51.58 & 1.74 & 37.1 & 45.9 & 45.0 & 8.8 & 7.9 \\
\hline${ }^{180} \mathrm{Hf}$ & ${ }^{48} \mathrm{Ca}$ & 52 & 80 & 79.64 & 1.28 & 54.3 & 44.0 & 42.8 & -10.3 & -11.5 \\
\hline${ }^{181} \mathrm{Ta}$ & & 53 & 80 & 81.68 & 1.52 & 47.6 & 43.6 & 43.6 & -3.9 & -3.9 \\
\hline${ }^{180} W$ & & 54 & 78 & 83.86 & 2.51 & 25.9 & 43.3 & 42.1 & 17.4 & 16.2 \\
\hline${ }^{182} W$ & & 54 & 80 & 84.09 & 1.77 & 40.7 & 42.6 & 41.4 & 1.9 & 0.7 \\
\hline${ }^{183} W$ & & 54 & 81 & 84.35 & 1.68 & 46.2 & 42.0 & 42.7 & -4.2 & -3.6 \\
\hline${ }^{184} W$ & & 54 & 82 & 84.94 & 1.66 & 43.9 & 40.9 & 39.7 & -3.0 & -4.2 \\
\hline${ }^{186} W$ & ${ }^{50} \mathrm{Ca}$ & 54 & 82 & 83.48 & 1.12 & 64.9 & 43.9 & 42.7 & 21.0 & -22.2 \\
\hline${ }^{185} \mathrm{Re}$ & ${ }^{48} \mathrm{Ca}$ & 55 & 82 & 86.95 & 2.19 & 32.8 & 40.7 & 40.7 & 7.8 & 7.8 \\
\hline${ }^{184} \mathrm{Os}$ & & 56 & 80 & 88.87 & 2.97 & 21.2 & 40.8 & 39.6 & 19.5 & 18.3 \\
\hline${ }^{187}$ Os & ${ }^{49} \mathrm{Ca}$ & 56 & 82 & 88.34 & 2.72 & 27.2 & 41.6 & 42.3 & 14.5 & 15.1 \\
\hline${ }^{188} \mathrm{Os}$ & ${ }^{52} \mathrm{Ti}$ & 54 & 82 & 94.75 & 2.14 & 34.4 & 42.8 & 41.5 & 8.4 & 7.1 \\
\hline${ }^{189}$ Os & ${ }^{53} \mathrm{Ti}$ & 54 & 82 & 94.27 & 1.97 & 41.9 & 43.8 & 44.5 & 1.9 & 2.5 \\
\hline${ }^{192} \mathrm{Os}$ & ${ }^{58} \mathrm{Cr}$ & 52 & 82 & 98.57 & 0.36 & 161.6 & 47.4 & 46.0 & -114.2 & -115.6 \\
\hline${ }^{191} \mathbf{I r}$ & ${ }^{56} \mathrm{Cr}$ & 53 & 82 & 102.39 & 2.08 & 37.1 & 44.4 & 44.4 & 7.4 & 7.4 \\
\hline${ }^{192} \mathrm{Pt}$ & ${ }^{56} \mathrm{Cr}$ & 54 & 82 & 105.41 & 2.41 & 31.2 & 43.2 & 41.8 & 12.0 & 10.6 \\
\hline${ }^{198} \mathrm{Pt}$ & ${ }^{68} \mathrm{Ni}$ & 50 & 80 & 113.74 & 0.09 & 399.3 & 48.3 & 46.7 & -351.0 & -352.6 \\
\hline${ }^{197} \mathrm{Au}$ & ${ }^{62} \mathrm{Fe}$ & 53 & 82 & 111.54 & 0.95 & 83.6 & 47.1 & 47.1 & -36.5 & -36.5 \\
\hline${ }^{196} \mathrm{Hg}$ & ${ }^{60} \mathrm{Fe}$ & 54 & 82 & 115.99 & 2.04 & 40.6 & 43.7 & 42.2 & 3.1 & 1.6 \\
\hline${ }^{202} \mathrm{Hg}$ & ${ }^{68} \mathrm{Ni}$ & 52 & 82 & 118.52 & 0.13 & 317.5 & 48.7 & 47.1 & -268.7 & -270.4 \\
\hline
\end{tabular}


"Present address: Central Institute of Physics, 76900 Bucharest, Romania.

1J. H. Hamilton, P. G. Hansen, and E. F. Zganjar, Rep. Prog. Phys. 48, 631 (1985).

${ }^{2}$ A. Sandulescu, D. N. Poenaru, and W. Greiner, Fiz. Elem. Chastits At. Yadra 11, 1334 (1980) [Sov. J. Part. Nucl. 11, 528 (1980)].

${ }^{3}$ D. N. Poenaru and M. Ivascu, Central Institute of Physics, Bucharest, Report No. NP-17, 1980, in Critical Phenomena in Heavy Ion Physics, Proceedings of the International School, Poiana Brasov, 1980, edited by A. Raduta and G. Stratan (Central Institute of Physics, Bucharest, 1980), p. 743.

${ }^{4}$ W. Greiner, M. Ivascu, D. N. Poenaru, and A. Sandulescu, Z. Phys. A 320, 347 (1985).

${ }^{5}$ D. N. Poenaru, M. Ivascu, A. Sandulescu, and W. Greiner, Joint Institute for Nuclear Research, Dubna, Report No. E4-84-446, 1984; Rep. Prog. Phys. (to be published).

${ }^{6}$ D. N. Poenaru and M. Ivascu, Central Institute of Physics, Bucharest, Report No. NP-39, 1984.

${ }^{7}$ D. N. Poenaru, M. Ivascu, A. Sandulescu, and W. Greiner, Phys. Rev. C 32, 572 (1985).

${ }^{8}$ H. J. Rose and G. A. Jones, Nature (London) 307, 245 (1984).

${ }^{9}$ D. V. Alexandrov, A. F. Beliatsky, Yu. A. Gluhov, E. Yu. Nikolsky, B. V. Novatsky, A. A. Ogloblin, and D. N. Stepanov, Pis'ma Zh. Eksp. Teor. Fiz. 40, 152 (1984) [JETP Lett. 40, 909 (1984)].

${ }^{10}$ S. Gales, E. Hourani, M. Hussonois, J. P. Schapira, L. Stab, and M. Vergnes, Phys. Rev. Lett. 53, 759 (1984); in Atomic Masses and Fundamental Constants, Proceedings of the 7th International Conference, Sept. 1984, Darmstadt, edited by O. Klepper (Tech- nische Hochschule, Darmstadt, 1984), p. 279.

${ }^{11}$ P. B. Price, J. D. Stevenson, J. D. Barwick, and H. L. Ravn, Phys. Rev. Lett. 54, 297 (1985).

${ }^{12}$ W. Kutschera, I. Ahmad, S. G. Armato III, A. M. Friedman, J. E. Gindler, W. Henning, T. Ishii, M. Paul, and K. E. Rehm, Phys. Rev. C (to be published).

${ }^{13}$ S. W. Barwick, P. B. Price, and J. D. Stevenson, Phys. Rev. C 31, 1984 (1985).

${ }^{14}$ A. Sandulescu, Yu. S. Zamiatnin, I. A. Lebedev, B. F. Miasoedov, S. P. Tretyakova, and D. Hasegan, JINR Rapid Communications, No. 5, 5 (1984).

${ }^{15}$ D. N. Poenaru, M. Ivascu, A. Sandulescu, and W. Greiner, J. Phys. G 10, L183 (1984); Central Institute of Physics, Bucharest, Report No. NP-41, 1985.

${ }^{16}$ A. Sandulescu, D. N. Poenaru, W. Greiner, and J. H. Hamilton, Phys. Rev. Lett. 54, 490 (1985).

${ }^{17}$ D. A. Bromley, in Clustering Aspects of Nuclear Structure, invited papers presented at the 4th International Conference, Chester, England, 1984, edited by J. S. Lilley and M. A. Nagarajan (Reidel, Dordrecht, 1985), p. 1.

${ }^{18} \mathrm{D}$. N. Poenaru and M. Ivascu, Central Institute of Physics, Bucharest, Report No. NP-27, 1983; J. Phys. (Paris) 45, 1099 (1984).

${ }^{19}$ Yi-Jin Shi and W. J. Swiatecki, Phys. Rev. Lett. 54, 300 (1985).

${ }^{20} \mathrm{~S}$. W. Barwick, H. L. Ravn, and P. B. Price (unpublished).

${ }^{21}$ A. H. Wapstra and G. Audi, Nucl. Phys. A432, 1 (1985).

${ }^{22}$ W. Seelmann-Eggebert, G. Pfennig, H. Münzel, and H. KeveNebenius, Nuklid Karte, 5th ed. (Kernforschungszentrum Karlsruhe, Karlsruhe, 1981). 